\title{
Case Files of the Drexel University Medical Toxicology Fellowship: Methadone-Induced QTc Prolongation
}

\author{
Stella C. Wong, DOa, James R. Roberts, $\mathrm{MD}^{a, b}$
}

aDepartment of Emergency Medicine, Division of Medical Toxicology, Drexel University College of Medicine, Philadelphia, PA

bDepartment of Emergency Medicine, Mercy Hospital of Philadelphia, Philadelphia, PA

\section{CASE PRESENTATION}

A 22-year-old man, on long-term methadone maintenance (125 mg daily), with a history of intermittent heroin abuse, came to the Emergency Department (ED) after ingesting $250 \mathrm{mg}$ of methadone. He was lethargic on presentation. Vital signs were: temperature $36.2{ }^{\circ} \mathrm{C}$; respiratory rate $10 / \mathrm{min}$; heart rate $50 / \mathrm{min}$; blood pressure 104/62 $\mathrm{mmHg}$; and room air oxygen saturation 99\%. A rapid beside glucose determination was $90 \mathrm{mg} / \mathrm{dl}$. His physical examination was significant for lethargy, "pinpoint" pupils and bradycardia, but was otherwise normal. No "track marks" or other stigmata of parenteral drug abuse were found. The cardiac monitor demonstrated sinus bradycardia. Toxicology was consulted. Clinically, this patient demonstrated a toxidrome consistent with opioid intoxication. An IV was established and a 12-lead EKG was performed, demonstrating sinus bradycardia (HR: $51 / \mathrm{min})$ with a markedly prolonged QTc $(516 \mathrm{~ms})$. A total of $0.6 \mathrm{mg}$ intravenous naloxone, $0.2 \mathrm{mg}$ every 5 minutes, was given with restoration of a normal mental status. A CBC of differential, basic metabolic panel, and serum calcium and magnesium levels were normal. A urine drug screen (UDS) was positive for methadone, benzodiazepine, and cocaine metabolite(s).

\section{Defining a Prolonged QTC}

The QT interval of the electrocardiogram (EKG) is measured from the beginning of the QRS complex to the end of the T wave. The QT interval is commonly corrected to reflect its inverse relationship to the heart rate. Bazett's formula is one of the commonly used formulas for QTc measurement, where QTc = QT interval (ms)/square root of the RR interval (s) [1]. For women, a QTc interval in considered prolonged when the interval is greater than
$450 \mathrm{~ms}$ to $470 \mathrm{~ms}$; for men, a QTc interval is considered prolonged when the interval is greater than $430 \mathrm{~ms}$ to $450 \mathrm{~ms}$ [1-3].

\section{What medications are known to cause QT prolongation?}

Table 1 provides a list of known medications that cause QT Prolongation [4].

\section{What is methadone?}

Methadone is a lipophilic synthetic opioid, and it is a standard detoxification treatment for opioid addiction. Methadone is an $\mu$ opiate-receptor agonist that has pharmacologic actions similar to morphine. The bioavailability of methadone after oral ingestion is between 36 to $100 \%$. It reaches peak plasma concentrations between 1 to 7.5 hours post-ingestion. The half-life varies widely between 8 to 59 hours. It is metabolized by the liver via N-demethylation by several P-450 isozymes (CYP3A4, CYP2B6, and CYP2C19) to form an inactive metabolite (2-ethylidene-1,5dimethyl-3,3-diphenylpyrrolidene [EDDP]) that is excreted in the urine [5].

\section{What factors affect methadone clearance?}

Since methadone is cleared via the liverhepatic dysfunction, congestive heart failure, and numerous medications alter serum clearance. Concomitant use of P-450 inducers, including phenytoin, phenobarbital and carbamazepine, enhance methadone clearance and may increase the incidence of opiate withdrawal. On the other hand, P-450 inhibitors, including antifungals and macrolide antibiotics, increase the serum methadone level by decreasing serum clearance, resulting in the potential increase in methadone toxicity [5].

Keywords: methadone, QTc prolongation, Torsades de Pointes.

Notes: There was no outside funding of any kind used for this study.

Corresponding Author: Stella C. Wong, New College Building, 2nd Floor, Mail Stop 1011, 245 North 15th Street, Drexel University College of Medicine, Philadelphia, PA 19102. Email: scw101@gmail.com 
Table 1: QT Prolongation Drugs [4]

\begin{tabular}{|c|c|c|}
\hline Albuterol & Fenfluramine & Ondansetron \\
\hline Alfuzosin & Flecainide & Paroxetine \\
\hline Amantadine & Fluconazole & Pentamidine \\
\hline Amiodarone & Fluoxetine & Phentermine \\
\hline Amitriptyline & Foscarnet & Phenylephrine \\
\hline Amoxapine & Fosphenytoin & Phenylpropanolamine \\
\hline $\begin{array}{l}\text { Amphetamine/ } \\
\text { dextroamphetamine }\end{array}$ & Galantamine & Pimozide \\
\hline Arsenic trioxide & Gatifloxacin & Procainamide \\
\hline Atomoxetine & Gemifloxacin & Protriptyline \\
\hline Azithromycin & Granisetron & Pseudoephedrine \\
\hline Bepridil & Halofantrine & Quetiapine \\
\hline Chloral hydrate & Haloperidol & Quinidine \\
\hline Chloropromazine & Ibutilide & Ranolazine \\
\hline Chloroquine & Imipramine & Risperidone \\
\hline Ciprofloxacin & Indapamide & Ritodrine \\
\hline Cisapride & Isoproterenol & Roxithromycin \\
\hline Citalopram & Isradipine & Salmeterol \\
\hline Clarithromycin & Itraconazole & Sertraline \\
\hline Clomipramine & Ketoconazole & Sibutramine \\
\hline Clozapine & Levalbuterol & Solifenacin \\
\hline Cocaine & Levofloxacin & Sotalol \\
\hline Desipramine & Levomethadyl & Sparfloxacin \\
\hline Dexmethylphenidate & Lithium & Tacrolimus \\
\hline Dextroamphetamine & Mesoridazine & Tamoxifen \\
\hline Disopyramide & Metaproterenol & Telithromycin \\
\hline Dobutamine & Methadone & Terbutaline \\
\hline Dofetilide & Methylphenidate & Thioridazine \\
\hline Dolasetron & Mexiletine & Tizanidine \\
\hline Domperidone & Midodrine & Tolterodine \\
\hline Dopamine & Moexipril/HCTZ & Trimethoprim-Sulfa \\
\hline Doxepin & Moxifloxacin & Trimipramine \\
\hline Droperidol & Nicardipine & Vardenafil \\
\hline Ephedrine & Norepinephrine & Venlafaxine \\
\hline Epinephrine & Nortriptyline & Voriconazole \\
\hline Erythromycin & Octreotide & Ziprasidone \\
\hline Felbamate & Ofloxacin & \\
\hline
\end{tabular}

\section{Is the misuse of methadone becoming more common?}

Methadone has become a popular street drug with a high potential for abuse. Between 2004 and 2005, the Drug Abuse Warning Network (DAWN), a public health surveillance system that monitors drug-related ED visits for the nation and for selected metropolitan areas, reported a $29 \%$ increase of ED visits related to the non-medical use of methadone [6]. There were 75 methadone-related fatalities reported in the Annual Report of the American Association of Poison Control Centers (AAPCC) in 2004 and 69 fatalities in 2005 [7]. Death in a majority of these cases was a result of intentional suicide, intentional abuse, or intentional misuse.

\section{How does methadone cause QTC prolongation?}

During normal myocardial repolarization, potassium ions exit the cells through potassium channels. There are $\mathrm{I}_{\mathrm{Kr}}$ (rapid component) and $\mathrm{I}_{\mathrm{Ks}}$ (slow component) channels. The human ethera-go-go-related gene (HERG) encodes the $\mathrm{I}_{\mathrm{Kr}}$ channel protein. Methadone blocks the human ether-a-go-go-related gene $\mathrm{K}^{+}$current $\left(\mathrm{I}_{\mathrm{HERG}}\right)$, diminishing the potassium efflux that triggers repolarization. When repolarization is delayed, the QT interval is prolonged $[8,9]$.

It has been suggested that the two, phenyl groups in methadone are responsible for the inhibitory effects on HERG. Even though the EDDP metabolite also contains two phenyl groups, it is a weaker inhibitor of HERG, perhaps related to its additional cyclic structure and positive charge [8].

\section{When was methadone-induced QTC prolongation first recognized?}

In 1973, Lipski and colleagues attempted to investigate the cause(s) of sudden death syndrome in heroin users. They performed EKGs on 75 asymptomatic patients admitted to a methadone maintenance program. In Group I, 34 patients received parenteral heroin and an EKG was performed prior to methadone administration. Group II consisted of 41 patients, on methadone for different durations, who concomitantly used other drugs, including barbiturates, heroin, cocaine, and alcohol. The investigators reported QTc prolongation in $19 \%$ of the patients in Group I and 34\% of the patients in Group II. They reported that "the most striking electrocardiogram" was a case of sudden death in a 31-year-old, longterm addict who was taking $100 \mathrm{mg} /$ day of methadone. This patient's EKG showed a QTc of $480 \mathrm{~ms}$, and the toxicological report was positive for methadone only [10]. However, methadoneinduced QTc prolongation was not truly appreciated until 2002 when Krantz and colleagues reported Torsades de Pointes in patients receiving high-dose methadone $[11,12]$. They reported a retrospective case series of 17 patients reported to have had Torsades de Pointes. These patients took $65 \mathrm{mg}$ to $1000 \mathrm{mg}$ of methadone daily for less than 1 month to greater than 12 months. Their QTc intervals ranged from $522 \mathrm{~ms}$ to $785 \mathrm{~ms}$ [11].

\section{Is QTc prolongation from methadone dose dependent?}

Factors including hypokalemia, concomitant use of CYP3A4 inhibitors, hepatic dysfunction, and higher maintenance doses of methadone were found to prolong the QTc in methadone maintenance patients [13]. Martell and colleagues reported that 
Table 2: Drugs with Risk of Torsades de Pointes [20]

\begin{tabular}{lll}
\hline Amidarone & Domperidone & Pentamidine \\
\hline Arsenic trioxide & Droperidol & Pimozide \\
\hline Bepridil & Erythromycin & Procainamide \\
\hline Chloroquine & Halofantrine & Quinidine \\
\hline Chlorpromazine & Haloperidol & Sotalol \\
\hline Cisapride & Ibutilide & Sparfloxacin \\
\hline Clarithromycin & Levomethadyl & Thioridazine \\
\hline Disopyramide & Mesoridazine & \\
\hline Dofetilide & Methadone & \\
\hline aNot available in the United States & \\
\hline
\end{tabular}

methadone-induced QTc prolongation was dose dependent. In this study, patients were initially started on $30 \mathrm{mg}$ oral methadone, increased to a median daily dose of $80 \mathrm{mg}$ by 6 months, and $90 \mathrm{mg}$ by 12 months. They found that QTc increased by $12.4 \pm 23 \mathrm{~ms}$ by 6 months and $10.7 \pm 30$ ms by 12 months [3]. QTc prolongation, however, has been reported with low-dose methadone therapy (14 $\mathrm{mg}$ /day) when hepatic metabolism of methadone is affected by other drugs [14]. Ehret and colleagues also reported that QTc prolongation occurred in patients taking methadone, $30 \mathrm{mg} /$ day [13]. Improvement in QTc prolongation was observed when methadone was stopped, suggesting that methadone was causative [14].

In contrast to other studies, Reddy and colleagues reported that daily median methadone doses of $30 \mathrm{mg}$ had no significant effect in QTc prolongation in 56 cancer patients. The mean QTc was $413 \mathrm{~ms}$ before and after methadone treatment [16]. No statistically significant QTc prolongation was found in another small prospective case series $(n=8)$ with mean oral methadone doses of $51 \mathrm{mg} /$ day at 2 weeks, $56 \mathrm{mg} /$ day at 3 months, and $57 \mathrm{mg} /$ day at 9 months. The mean QTc intervals were $420 \mathrm{~ms}$ at baseline, 440 $\mathrm{ms}$ at 2 weeks, $430 \mathrm{~ms}$ at 3 months, and $430 \mathrm{~ms}$ at 9 months [17].

The exact dose of methadone required to produce clinically significant QTc prolongation is unknown. However, QTc prolongation is, in our opinion, likely to be dose-related. QTc interval prolongation $(>500 \mathrm{~ms}$ ) is a prominent risk factor for Torsades de Pointes and sudden cardiac death [1]. High dose methadone $(>60$ $\mathrm{mg} /$ day) has been reported to cause Torsades de Pointes $[11,18,19]$.

\section{What other medications cause Torsades de Pointes?}

Table 2 and Table 3 provide a list of known medications that cause Torsades de Pointes [20,21].

\section{Could cocaine be the cause of QTc prolongation in our patient?}

Our patient had a positive urine drug screen for cocaine. Cocaine has also been shown to prolong the QTc by the same mechanism as methadone [22]. Magnano and colleagues reported statistically significant QTc prolongation and heart rate elevation in fourteen

\section{Table 3: Drugs with Risk of Torsades de Pointes [21]}

\begin{tabular}{lll}
\hline Alfuzosin & Granisetron & Ranolazine \\
\hline Amantadine & Indapamide & Risperidone \\
\hline Azithromycin & Isradipine & Roxithromycina \\
\hline Chloral hydrate & Levofloxacin & Tacrolimus \\
\hline Clozapine & Lithium & Tamoxifen \\
\hline Dolasetron & Moexipril/HCTZ & Telithromycin \\
\hline Felbamate & Moxifloxacin & Tizanidine \\
\hline Flecainide & Nicardipine & Vardenafil \\
\hline Foscarnet & Octreotide & Venlafaine \\
\hline Fosphenytoin & Ofloxacin & Voriconazole \\
\hline Gatifloxacin & Ondansetron & Zipradidone \\
\hline Gemifloxacin & Quetiapine & \\
\hline
\end{tabular}

${ }^{a}$ Not available in the United States

habitual cocaine users. The subjects smoked $25 \mathrm{mg}$ of cocaine, and the QTc interval increased by $15 \mathrm{~ms}$ within 2 minutes and lasted throughout the 12 minute observation period [23]. Gamouras and colleagues reported that QTc prolongation after cocaine use could be delayed for up to 24 to 48 hours [24].

Our patient was bradycardic, so it is unlikely that his QTc prolongation was secondary only to acute cocaine use. Methadone has also been reported to cause bradycardia $[25,26]$. Because the structure of methadone is similar to verapamil, it is suggested that methadone decreases heart rate by blocking the calcium channels [27]. In addition, bradycardia may increase the chance for Torsades de Pointes by prolonging the QTc interval because the heart rate and QTc are inversely related.

\section{What is the management for methadone overdose and methadone-induced QTC prolongation?}

Naloxone may be given as an antidote for methadone overdose, especially for patients presenting with an opioid toxidrome (miosis and decreased blood pressure, heart rate, respiratory rate, and mental status). Patients who overdose on methadone should be admitted to a monitored unit because methadone has a long halflife allowing for delayed and/or recurrent toxicity, even if the initial toxidrome can be reversed with naloxone.

Methadone administration should be stopped or the dosage decreased. Toxicologists should correct underlying electrolyte abnormalities (hypokalemia, hypocalcemia, and hypomagnesemia) and follow Advanced Cardiac Life Support (ACLS) protocol for symptomatic bradycardia, prolonged QTc, and/or Torsades de Pointes.

\section{CASE CONTINUATION}

Because of the long half-life of methadone and the prolonged QTc, the patient was admitted to the intensive care unit for close 
monitoring. The patient did not receive any methadone during hospitalization, and-except for mild opiate withdrawal- he experienced no untoward events. The QTc returned to normal (425 ms) on hospital day 3.

\section{FINAL NOTE}

Methadone can prolong the QTc interval to a degree that predisposes methadone-users to malignant cardiac arrhythmias. Recently, the FDA MedWatch issued a warning titled "Methadone Use for Pain Control May Result in Death and Life-Threatening Changes in Breathing and Heart Beat" [28]. The exact dose and circumstances of methadone-induced prolonged QTc are not fully defined. Individuals who overdose on methadone, those on high maintenance doses of methadone ( $>60 \mathrm{mg} /$ day), and those at the initiation of therapy seem at highest risk. EKG evaluation and continuous cardiac monitoring of patients who overdose on methadone is prudent.

The authors have no potential conflicts of interest to report.

\section{REFERENCES}

1. Al-Khatib SM, LaPointe NM, Kramer JM, Califf RM. What clinicians should know about the QT interval. JAMA.

2003;289:2120-2127.

2. Kornick CA, Kilborn MJ, Santiago-Palma J, Schulman G, Thaler HT, Keefe DL, Katchman AN, Pezzullo JC, Ebert SN, Woosley RL, Payne R, Manfredi PL. QTc interval prolongation associated with intravenous methadone. Pain.

2003;105:499-506.

3. Martell BA, Arnsten JH, Krantz MJ, Gourevitch MN. Impact of methadone treatment on cardiac repolarization and conduction in opioid users. Am J Cardiol. 2005;95:915-918.

4. Arizona CERT (Center for Education and Research on Therapeutics) [webpage on the Internet]. Drugs That Prolong the QT Interval and/or Induce Torsades de Pointes. [updated 2006 Mar 1, cited 2007 May 1]. Available from: http://www .qtdrugs.org/medical-pros/drug-lists/pubMed-drug-list.cfm

5. Dolophine ${ }^{\circledR}$ Hydrochloride CII (Methadone

Hydrochloride Tablets, USP). Roxane Laboratories, INC.

Columbus, $\mathrm{OH} 43216$.

6. Drug Abuse Warning Network [webpage on the Internet]. Drug Abuse Warning Network, 2005: National Estimates of DrugRelated Emergency Department Visits. [updated 2007 Mar, cited 2007 June 4]. Available from: http://dawninfo.samhsa.gov/ files/DAWN-ED-2005-Web.pdf

7. Lai MW, Klein-Schwartz W, Rodgers GC, Abrams JY, Haber DA, Bronstein AC et al. 2005 Annual Report of the American Association of Poison Control Centers' National Poisoning and Exposure Database. Clinical Toxicology. 2006;44(6 \& 7):803-932.

8. Katchman AN, McGroary KA, Kilborn MJ, Kornick CA, Manfredi PL, Woosley RL, Ebert SN. Influence of opioid agonists on cardiac human ether-a-go-go-related gene $\mathrm{K}^{+}$currents. J Pharmacol Exp Ther. 2002;303:688-694.

9. Nelson LS: Toxicologic myocardial sensitization. Journal of Toxicology: Clinical Toxicology. 2002;40:867-879.

10. Lipski J, Stimmel B, Donoso E. The effect of heroin and multiple drug abuse on the electrocardiogram. American Heart Journal. 1973;86(5):663-668.

11. Krantz MJ, Lewkowiez L, Hays H, Woodroffe MA, Robertson AD, Mehler PS. Torsade de pointes associated with very-high-dose methadone. Ann Intern Med. 2002;137:501-504.

12. Krantz MJ, Mehler PS. QTc prolongation: methadone's efficacy-safety paradox. The Lancet. 2006;368:556-557.

13. Ehret GB, Voide C, Gex-Fabry M, Chabert J, Shah D, Broers B, Piguet, V, Musset T, Gaspoz JM, Perrier A, Dayer P, Desmeules JA. Drug-induced long QT syndrome in Injection drug users receiving methadone. Arch Intern Med.

2006; 166 :1280-1287.

14. Piguet V, Desmeules J, Ehret G, Stoller R, Dayer P. QT interval prolongation in patients on methadone with concomitant drugs. Journal of Clinical Psychopharmacology. 2004;24(4):446-8.

15. Decerf JA, Gressens B, Brohet C, Liolios A, Hantson P. Can methadone prolong the QT interval? Intensive Care Med. 2004; $30: 1690-1691$.

16. Reddy S, Fisch M, Bruera E. Oral methadone for cancer pain: no indication of Q-T interval prolongation or torsades de pointes. Journal of Pain and Symptom Management.

2004;28(4):301-303.

17. Fredheim OM, Borchgrevink PC, Hegrenaes L, Kaasa S, Dale O, Klepstad P. Opioid switching from morphine to methadone causes a minor but not clinically significant increase in QTc time: a prospective 9-month follow-up study. J Pain Symptom Manage. 2006;32:180 -185.

18. Sticherling C, Schaer BA, Ammann P, Maeder M, Osswald S. Methadone-induced torsade de pointes tachycardias. Swiss Med Wkly. 2005;135:282-285.

19. Lamont P, Hunt SC. A twist on torsade: a prolonged QT interval on methadone. J Gen Intern Med. 2006;21:C9-C12.

20. Arizona CERT (Center for Education and Research on Therapeutics) [webpage on the Internet]. Drugs with Risk of Torsades de Pointes. [updated 2006 Mar 1, cited 2007 June 4]. Available from: http://www.torsades.org/medical-pros/ drug-lists/list-01.cfm.

21. Arizona CERT (Center for Education and Research on Therapeutics) [webpage on the Internet]. Drugs with Risk of Torsades de Pointes. [updated 2006 Mar 1, cited 2007 June 4]. Available from: http://www.torsades.org/medical-pros/druglists/list-02.cfm.

22. Ferreira S, Crumb WJ, Carlton CG, Clarkson CW. Effects of cocaine and its major Metabolites on the HERG-encoded potassium channel. J Pharmacol Exp Ther. 2001;299:220-226.

23. Magnano AR, Talathoti NB, Hallur R, Jurus DT, Dizon J, Holleran S, Bloomfield DM, Collins E, Garan H. Effect of acute cocaine administration on the QTc interval of habitual users. Am J Cardiol. 2006;97:1244-1246. 
24. Gamouras GA, Monir G, Plunkitt K, Gursoy S, Dreifus L. Cocaine abuse: repolarization abnormalities and ventricular arrhythmias. Am J Med Sci. 2000;320(1):9-12.

25. Ashwath ML, Ajjan M, Culclasure T. Methadone-induced bradycardia. The Journal Emergency Medicine. 2005;29(1):73-5.

26. Wheeler AD, Tobias JD. Bradycardia during methadone therapy in an infant. Pediatr Crit Care Med. 2006;7(1):83-85.
27. Seyler DE, Borowitz JL, Maickel RP. Calcium channel blockade by certain opioids. Fundam Appl Toxicol. 1983;3:536-542.

28. U.S. Food and Drug Adminstration [webpage on the internet]. Methadone Use of Pain Control May Result in Death and Life-Threatening Changes in Breathing and Heart Beat. [created 2006 Nov 27]. Available from: http://www.fda.gov/cder/drug/ advisory/methadone.htm. 